\title{
Cuidado, Maternidade e Racismo: Reflexões entre Psicologia e Assistência Social
}

\author{
Cuidado, Maternidad y Racismo: Reflexiones entre Psicología y Asistencia Social
}

Caring, Maternity and Racism: Considerations between Psychology and Social Assistance

Thais Gomes de Oliveira

ORCID: https://orcid.org/0000-0002-0126-1988 Universidade Federal do Rio Grande do Sul, Rio Grande do Sul/Brasil

Bruna Moraes Battistelli

ORCID: https://orcid.org/0000-0003-0973-0934 Universidade Federal do Rio Grande do Sul, Rio Grande do Sul/Brasi

Lílian Rodrigues da Cruz

ORCID: https://orcid.org/0000-0002-1850-3023 Universidade Federal do Rio Grande do Sul, Rio Grande do Sul/Brasill

Declaração de Direito Autoral

A submissão de originais para este periódico implica na transferência, pelos autores, dos direitos de publicação impressa e digital. Os direitos autorais para os artigos publicados são do autor, com direitos do periódico sobre a primeira publicação. Os autores somente poderão utilizar os mesmos resultados em outras publicações indicando claramente este periódico como o meio da publicação original. Em virtude de sermos um periódico de acesso aberto, permite-se o uso gratuito dos artigos em aplicações educacionais e científicas desde que citada a fonte conforme a licença CC-BY da Creative Commons.

\section{Resumo}

Como narrar histórias de vidas acompanhadas na Assistência Social? Pergunta que move este ensaio que é pensado a partir da interface entre Psicologia e Assistência Social e objetiva discutir as relações entre performance de maternidade, cuidado e racismo nas políticas públicas de Assistência Social. Um ensaio que se constitui a partir do entrelaçamento de narrativas de mulheres e reflexão teórica. Para isso, vale-se de histórias de mulheres, dados sobre o genocídio da população negra pautado por estatísticas de violência policial e estatal, que faz de mulheres-mães também vítimas: mulheres órfãs de filhas/os vivas/os. Inspiradas por Jorge Larrosa, lançamo-nos ao ensaio enquanto constituição do pensamento. Ensaiar sobre a maternidade em contexto da Assistência Social nos leva a problematizar as relações entre cuidado e violência, interseccionadas pelas relações raciais. Temas como raça, racismo, genocídio da população negra, maternidade, cuidado e Assistência Social constituem o eixo problemático deste ensaio. Utilizamo-nos do ensaio como dispositivo para refletir sobre possibilidades para a constituição de narrativas femininas na Assistência Social.

Palavras-chave: Maternidade; Racismo; Psicologia social; Assistência social.

\section{Resumen}

¿Cómo narrar historias de vidas acompañadas en la Asistencia Social? Pregunta que mueve este ensayo que se piensa a partir de la interfaz entre Psicología y Asistencia Social y objetiva discutir las relaciones entre desempeño de maternidad, cuidado y racismo en las políticas públicas de la Asistencia Social. Un ensayo que se constituye a partir del entrelazamiento de narrativas de mujeres y reflexión teórica. Para ello, se vale de historias de mujeres, datos sobre el genocidio de la población negra - pautado por estadísticas de violencia policial y estatal, que hace de mujeres madres también 
víctimas: mujeres huérfanas de hijos e hijas vivos. Inspiradas por Jorge Larrosa, nos lanzamos al ensayo como constitución del pensamiento. El ensayo sobre la maternidad en el contexto de la Asistencia Social nos lleva a problematizar las relaciones entre cuidado y violencia, interseccionalizadas por las relaciones raciales. Temas como raza, racismo, genocidio de la población negra, maternidad, cuidado y asistencia social constituyen el eje problemático de este ensayo. Utilizamos del ensayo como dispositivo para reflexionar sobre posibilidades para la constitución de narrativas femeninas en la Asistencia Social.

Palabras clave: Maternidad; Racismo; Psicología social; Asistencia social.

\begin{abstract}
How to narrate the stories of lives followed by Social Assistance? Question that moves this essay which is thought from the interface between Psychology and Social Assistance and has as an objective to discuss the relations among maternity performance, caring and racism on the Social Assistance public policies. An essay that is based on the interlacing of women's narratives and theoretical thinking. For such, we make use of women's stories, data on the genocide of the black people - based on statistics regarding police and state violence, which makes mothers-women also victims: orphan women of alive children. Inspired by Jorge Larrosa, we opt for the essay as a constitution of thinking. Essaying about maternity in the Social Assistance context brings us to problematize the relations between caring and violence, intersectionalised by racial relations. Themes like race, racism, black people genocide, maternity, caring and Social Assistance constitute the problematic axis of this essay. We make use of the essay as a device to reflect on the possibilities for the constitution of female narratives in Social Assistance.
\end{abstract}

Keywords: Maternity; Racism; Social psychology; Social assistance.

\section{Narrativas possíveis na Assistência Social}

Invento? Sim invento, sem o menor pudor. Então as histórias não são inventadas? Mesmo as reais, quando são contadas. Desafio alguém a relatar fielmente algo que aconteceu.

Entre o acontecimento e a narração do fato, Alguma coisa se perde e por isso se acrescenta.

(Evaristo, 2017)

Este ensaio tem como objetivo discutir relações entre maternidades, cuidado e racismo. Nosso cenário é o da Assistência Social e nossa implicação com o campo se dá pela pesquisa acadêmica em Psicologia Social que acontece a partir de análises de documento e inserções no campo. Mas neste trabalho, nos propomos a pensar sobre um tema que tem nos instigado: a responsabilização de mulheresmães e como as mesmas sofrem com a desigualdade social a que estão expostas e com diferentes formas de violência social. Para a escrita do mesmo optamos por dialogar com reportagens e crônicas que falam de mulheres que perderam seus filhos para a violência: mulheres que se veem frente à uma morte anunciada de seus filhos e filhas. Tomamos para discussão as múltiplas formas de violência possíveis que mulheres-mães são expostas frente à um cenário de desigualdade social e acirramento de diferenças: a mãe que por viver em situação de rua moradia não pode exercer a maternidade; a mulher que vê seus filhos serem levados a instituição de acolhimento por pobreza; a mãe responsabilizada pela pobreza de sua família ou pela violência do companheiro. Mulheres que sofrem inúmeras formas de violências e que, muito frequentemente, precisam encarar o luto por seus filhos que perecem frente ao cenário seletivo da violência letal. Perda, neste cenário, se apresenta de diferentes formas, que 
trataremos como pequenas mortes do cotidiano.

Abrimos este ensaio com Conceição Evaristo e questionamos: o que é possível narrar? Implicadas com o mundo que nos toca, produzimos narrativas que intencionam construir uma escrita do/pelo cuidado. Cuidado conceituado enquanto aquilo que ocorre em ato, na relação, enquanto acontecimento (Merhy, 2006). Escolher um jeito de narrar é colocar camadas, gravando no papel os rastros das experiências.

Agora a escrita não é mais um rastro privilegiado, mais duradouro do que outras marcas da existência humana. Ela é rastro [...] rastro que é fruto do acaso, da negligência, às vezes da violência; deixado por um animal que corre ou por um ladrão em fuga, ele denuncia uma presença ausente sem, no entanto, prejulgar sua legibilidade (Gagnebin, 2009, p. 113).

Buscamos formas de narrar algo dessas vidas sobreviventes, encontramos $\mathrm{o}$ ensaio enquanto forma outra de escrever, de pensar, de oferecer lugar possível nessa escrita que exista a partir da nossa forma presente de ver/ler o mundo. Tenta-se dar movimento a histórias que se escutou e que, a partir do testemunho, podem ser contadas neste espaço. O ensaio, a partir de então, pode ser um modo de lidar com a realidade, uma maneira - em sua forma mais variada - de habitar o mundo e/ou de escrever sobre ele (Larrosa, 2004). E aqui, tomamos o ensaio enquanto exercício de produção de pensamento. Um ensaio que versa sobre experiências maternas que acompanhamos em reportagens e que dialogam com o nosso interesse de pesquisa com o qual trabalhamos: a matricialidade sociofamiliar e a constituição do trabalho social com famílias. Eliane Brum (2016), autora do texto 'Mães Vivas de Uma Geração Morta', nos inspira a nos debruçarmos sobre como se constituem mulheres-mães-órfãs e como estas são predominantemente mulheres negras e pobres; um genocídio que perpassa a Assistência Social.

A partir desse cenário, problematizamos a centralidade da maternidade na Política de Assistência Social e, assim, colocamos relações entre cuidado, racismo e violência em evidência. Pequenas mortes do cotidiano, que se iniciam pelo acirramento da desigualdade social que em nosso país diz da desigualdade racial, onde negras/os e indígenas encontram-se sempre em desvantagem quanto à população branca. Pequenas mortes que passam pela falta de acesso, serviços precários, poucas oportunidades, encarceramento em massa, subempregos, mortes violentas etc. Crianças e famílias que parecem fadadas a um destino cruel e esperado. Mulheres que sobrevivem ao assassinato de seus filhos ou filhas... Crianças, adolescentes e jovens que morrem cedo demais...

São mulheres acompanhadas por serviços de diferentes políticas públicas, que muitas vezes são beneficiárias do Programa Bolsa Família, que tem seus filhos acompanhados por diferentes profissionais dessas políticas - de saúde, educação e assistência -, que veem seus filhos e filhas perderem a vida por violência letal. Mortos, em sua maioria pela polícia ou pelo tráfico, deixam mães órfãs. Para elucidar o que estamos tratando, seguem algumas micronarrativas ${ }^{1}$ : [...] Um dia não suportei. Estava só eu e meu filho dentro de casa. Decidi botar fogo em nós dois. O filho de Maria Fátima da Silva Souza foi assassinado em abril. Ela sobreviveu. [...] $\mathrm{O}$ primeiro que morreu era pequenininho, desse tamanhinho assim. Setenta e oito facadas. Tinha 13 anos. Helena Silva Cruz perdeu dois filhos. O último

\footnotetext{
${ }^{1}$ Estas micronarrativas fazem parte de uma reportagem da Revista Época, acessada em 08/07/2018, http://revistaepoca.globo.com/Revista/Epoca/0.,EDG74 909-6014,00$\underline{\mathrm{MEU}+\mathrm{FILHO}+\mathrm{FOI}+\mathrm{ASSASSINADO} . \mathrm{html}}$
} 
virou assassino ao vingar um dos irmãos no ano passado. Ela sobreviveu. [...] Quando meu filho apareceu em casa vivo, mas com um tiro no peito, comecei a pagaro caixão. $\mathrm{O}$ filho de Enilda Rodrigues da Silva foi executado pouco antes do Natal. Ela sobreviveu. [...] Quando morreu o terceiro, achei que fosse morrer também e comprei uma mortalha de tergal branco. Quem morreu foi minha filha. Vesti nela a mortalha que era pra mim. Selvina Francisca da Silva perdeu quatro filhos, um sumiu. Ela sobreviveu. [...] Meu filho levou um tiro na barriga que atravessou. A polícia disse que o único trabalho da família era enterrar. $\mathrm{O}$ filho de Josefa Inacio Farias foi assassinado em março. Ela sobreviveu. [...] $\mathrm{Meu}$ filho gritava porque estava perdendo muito sangue. A polícia ouviu, arrombou a porta e ele morreu. O tráfico pagou o enterro. O filho de Francisca Maria da Silva Porfirio foi morto em março. Ela sobreviveu. [...] Meu terceiro morreu na boca de fumo. Tinha 22 anos. Minha cabeça bate. Parece que tem um tambor. Ouço esse barulho dia e noite. Eva Sebastiana Araújo perdeu três filhos, o último em 2002. Ela sobreviveu. [...] Não fui ao enterro de nenhum dos meus filhos. Se pudesse, eu me enterrava. Graça Mary Azevedo Carneiro perdeu o último filho em janeiro. Ela sobreviveu. ${ }^{2}$ Mulheres que nos fazem pensar em existência, nas possibilidades destas existências mínimas existirem. Lapoujade (2017, p. 20) afirma que "os modos de existência são ocupações de espaçostempos, contanto que fique claro que cada modo de existência cria o espaço-tempo que ocupa". Mulheres que nos fazem lembrar dos vaga-lumes e da discussão de Didi-Huberman.

Primeiro, desapareceram mesmo os vaga-lumes? Desapareceram todos? Emitem ainda - mas de onde? - seus maravilhosos sinais intermitentes?

\footnotetext{
2 Por uma escolha estilística em nosso ensaio mantivemos as narrativas que aparecem na reportagem enquanto pequenas manchetes no texto e citadas uma seguida da outra.
}

Procuram-se ainda em algum lugar, falam-se, amam-se apesar de tudo, apesar do todo da máquina, apesar da escuridão da noite, apesar dos projetores ferozes? $\left(2011, \mathrm{~s} / \mathrm{p}^{3}\right)$

Sobrevivência! Os vaga-lumes sobrevivem apesar de tudo, diz o autor. Assim como as mulheres que tem seus filhos e suas filhas mortos/as; essas que se veem sem poder cuidá-los/as; essas que vão "costurando suas vidas com fios de ferro"4; essas que vão criando formas de sustentar uma existência que muito lhes é negada. Elas sobrevivem. São elas que vão viver na tentativa de responder ao que lhes é demandado e esperado. Mulheres que tem/terão suas vidas e práticas de cuidado judicializadas, sua intimidade escrutinada por diferentes serviços das políticas públicas. Mulheres que serão mais facilmente destituídas dos seus direitos. Mulheres que são/serão julgadas como negligentes quando seus/suas filhos/as se constituírem em mais um assassinato nas estatísticas da segurança pública. Recorremos a Evaristo (2016). E trazemos aqui, a partir dela, um pequeno pedaço da história de Duzu-Querença

Duzu morou ali muitos anos e de lá partiu para outras zonas. Acostumouse aos gritos das mulheres apanhando dos homens, ao sangue das mulheres assassinadas. Acostumou-se às pancadas dos cafetões, aos mandos e desmandos das cafetinas. Habituou-se à morte como forma de vida. Os filhos de Duzu foram muitos. Nove. Estavam espalhados pelos morros, pelas zonas e pela cidade. Todos os filhos tiveram filhos. Nunca menos de dois. Dentre os seus netos, três

\footnotetext{
${ }^{3}$ PDF utilizado não tinha marcação de páginas. Assim, todas as referências ao livro de Didi-Huberman ficaram com a especificação s/p.

${ }^{4}$ Expressão de Conceição Evaristo (2016) em seu livro Olhos d'Água - conto “A gente combinamos de não morrer"
} 
marcavam assento maior em seu coração. Três netos lhe abrandavam os dias. (Evaristo, 2016, p. 34).

Nessa escrita de Conceição, lemos através de seus olhos uma certa vida. Conceição escreve que Duzu viveu a morte de Tático, um de seus três netos. E que

Estava chegando uma época em que o sofrer era proibido. Mesmo com toda dignidade ultrajada, mesmo que matassem os seus, mesmo com a fome cantando no estômago de todos, com o frio rachando a pele de muitos, com a doença comendo o corpo, com o desespero diante daquele vivermorrer, por maior que fosse a dor, era proibido sofrer. Ela gostava desse tempo. Alegrava-se tanto! Era carnaval. (Evaristo, 2016, p. 35)

Com Conceição aprendemos a escrever vidas não hegemônicas e que não encontram lugar e acolhimento nas narrativas "oficiais". Conceição produziu suas escrevivências a partir de sua experiência de mulher negra em relação com a ancestralidade de um coletivo de mulheres que compartilham histórias da violência, escravidão de seus antepassados e vivência de uma série de desigualdades que são particulares às mulheres negras no cenário nacional. Conceição escreve sobre a violência da vida, sem perder as possibilidades e alegrias que fazem parte dessas experiências e sem romantizar a violência cotidiana.

\section{Narrativas de maternidade: relações entre racismo e cuidado}

"Quem pariu os seus que os embale": Priscilla Bezerra Barbosa (2017) ${ }^{5}$ lembra dessa expressão popular, ao escrever sobre maternidade. Quantas coisas diz essa frase na construção da função da maternidade no

\footnotetext{
5 Autora do livro intitulado "O filho é da mãe?"
}

imaginário da nossa cultura? Que o filho é da mãe. Que é sua a responsabilidade pelo cuidado, guarda, sustento, embalo. Que é da mulher-mãe, e não do homem que é pai, a responsabilidade pelos filhos. Que essas mulheres-mães devem.

Narrativas de maternidade se relacionam com cuidado. E nos perguntamos: como foi que o cuidado do outro foi incumbido às mulheres? Como foi que as Políticas de Assistência Social também se vincularam a essa ideia de maternidade, de uma determinada função materna? $\mathrm{Na}$ tentativa de encontrarmos pistas, nos encontramos com essa mesma autora, mulher negra e mãe e acadêmica, que nos conta que

[...] a maternidade ainda é concebida pela sociedade como ferramenta válida para o acirramento da opressão e da violência contra mulheres, a partir da constatação sobre a existência do que Biroli (2014) chama de "treinamento social para o cuidado com os outros", sejam estes os mais velhos ou os filhos. (Barbosa, 2017, p. 116)

Existe uma construção de cidadania que é passada pelo lugar que é possível à mulher ocupar. $\mathrm{O}$ espaço muitas vezes considerado privado da maternidade é um dos que está garantido e/ou imposto. E é impossível falar sobre cidadania e maternidade, sem falar sobre raça e classe. Cabe ainda mais às mulheres negras e pobres o julgamento pelo que acontece com seus filhos; o julgamento pelo que seus filhos são acometidos. Em se tratando de uma sociedade desigual, essas mulheres que são responsabilizadas, muitas vezes unicamente, pelo cuidado "dos seus", são culpabilizadas por toda adversidade existente; por tudo que sofrem. E são muito mais essas mulheres negras e pobres que vão criar seus filhos em um cenário de genocídio: genocídio dos jovens 
negros. Se repetimos as ideias e palavras é para demarcar a urgência que essas situações apresentam e a necessidade de pensarmos sobre elas.

Não vemos outra saída possível - na tentativa de narrarmos sobre racismo, cuidado e maternidade - senão falando de mortes e de violências: se a cada dia 30 crianças e adolescentes são assassinados no $\mathrm{Brasil}^{6}$, a cada dia 30 mulheres tornam-se órfãs de seus filhos e filhas. Mulheres como as narradas por Eliane Brum, precisam conviver com a dor, com a resignação, com o luto e com uma infinidade de pré-julgamentos a que seus filhos e suas famílias são submetidos. Narrativas que se proliferam anunciando uma certa "culpa" daquele que morreu. Uma "quase predestinação", produzida por uma lógica racista e uma orfandade de mulheres. Uma orfandade que se apresenta em números que alimentam as estatísticas: a mesma reportagem citada acima, segue afirmando que "com uma taxa de 4,3 homicídios por 100 mil habitantes, o Brasil é o terceiro país mais violento para crianças e adolescentes de 10 a 14 anos em uma lista de 85 nações". Em números absolutos, o Brasil é o segundo país com maior quantidade de crianças e adolescentes assassinados, ficando atrás apenas da Nigéria. Um risco de morte que se inicia na profunda desigualdade social brasileira que é pautada por um abismo racial: é a população negra que povoa os índices de desigualdade, as estatísticas de violência letal, os maiores números de feminicídio, o baixo acesso a serviços de qualidade, o acesso a empregos de baixa garantia etc. Uma série longa de acirramento da violência estatal e da produção de mortes anunciadas desde muito antes o nascimento das pessoas.

\footnotetext{
6 Reportagem acessada pelo seguinte endereço: https://oglobo.globo.com/brasil/a-cada-dia-30-criancasadolescentes-sao-assassinados-no-brasil-

22179837\#ixzz5KFjpKBea (acesso em 15 de setembro de 2018).
}

Mas o que estamos produzindo/fazendo quando os números nos contam uma história de genocídio? Números de uma violência que colocam o Brasil em um patamar muito próximo a países em guerra declarada. A população negra e pobre, além de ter seus direitos retirados em grande escala é a que mais morre nas cidades brasileiras. Na mesma reportagem citada acima, aponta-se que "homens e mulheres negras estão no centro do projeto de extermínio entre 2006 e 2016, a taxa de homicídios de negros cresceu $23,1 \%$ ". Ao mesmo tempo, a taxa entre os não negros teve uma redução de $6,8 \%$. Ressalta-se que a taxa de homicídios de mulheres negras foi $71 \%$ superior à de mulheres não negras no mesmo período. O Atlas da Violência de 2018 nomeia de juventude perdida a faixa etária entre 15 e 29 anos que sofre com o escalonamento dos casos de violência, tendo os homicídios como causa da morte de 56,5\% desta parcela da população. De modo geral, as violências contra a população negra (pretos e pardos) aumentou em 23,1\% nos últimos 10 anos. (IPEA, 2018).

Múltiplas mortes, vidas nuas, vidas sem valor jurídico (Agamben, 2002). "Como pensar a vida, postulada como insacrificável, e ao mesmo tempo convertida em algo descartável, capturada como vida nua?" (Candiotto, 2011, p. 87). Um entrelaçamento que nos instiga a problematizar como o tema da raça é invisibilizado no campo da Assistência Social. Que nos traz para essa necessidade de pensarmos sobre mulheres violentadas cotidianamente pelo agravamento das desigualdades sociais, expostas ao sofrimento e ao risco.

Lembro da primeira vez que vi uma mulher com o corpo cheio de hematomas produzidos pelo companheiro. E do como ela juntou suas forças, filhos e coisas e mudouse para outra cidade em poucas horas. Lembro da primeira vez que ouvi uma adolescente contar a violência sexual que sofreu do pai, e a dor que sentia por sentir saudades do mesmo. 
Assim como lembro da mulher que precisou identificar os sobrinhos no IML. Lembro de que falei com ela por telefone, minutos depois desse processo de reconhecer dois adolescentes no IML. O medo que ela sentia, a angústia em como contar para as filhas o ocorrido, as dúvidas sobre como custear dois funerais. Vidas tiradas a tiros, sobrevivências marcadas pela violência... eu devia estar falando de existências e de resistências, mas antes preciso falar de morte, dor e luto (Trecho de diário de campo dia 20/07/2018).

Como se produzem as mortes que acontecem o tempo todo no Brasil? Quantas são as práticas que se relacionam com números tão alarmantes e assustadores de violências? A violência de Estado acontece também quando uma parte das pessoas no país - as negras e pobres - é a que mais é encarcerada, institucionalizada, assassinada; quando desde o nascimento essas pessoas são mais reguladas pelas políticas públicas; quando os direitos sociais básicos não são garantidos a essa parte da população. As mulheres negras perdem mais os seus filhos, seja para os assassinatos, seja para o acolhimento institucional.

Práticas maternas atravessadas pela violência cotidiana; um cuidado sempre em risco e mediado pelo racismo que constitui o Estado brasileiro. A negação da memória da escravidão faz com que as relações de desigualdades sejam mais acirradas quando miramos um recorte racial. A parcela mais pobre e vítima de uma política de extermínio estatal no país é de pessoas negras. Assim, a falta de garantias de direitos transforma-se em produtor de pequenas mortes cotidianas. Vidas fadadas ao extermínio. Vidas sacras que podem ser mortas.

É como se toda valorização e toda "politização" da vida implicasse necessariamente uma nova decisão sobre o limiar além do qual a vida cessa de ser politicamente relevante, é então somente "vida sacra" e, como tal, pode ser impunemente eliminada. [...] Toda sociedade fixa esse limite, toda sociedade-mesmo a mais moderna- decide quais sejam seus "homens sacros" (Agamben, 2002, p. 146).

Mortes vão sendo produzidas... São as mesmas crianças e adolescentes com os menores índices de investimento em políticas públicas, com os piores acessos a serviços, que vivem os impactos dos maiores índices de vulnerabilidade, que moram nos territórios periféricos que são alvo de violência, que cedo se iniciam no trabalho precarizado e mal remunerado, que circulam por entre abrigos, empurradas para o trabalho informal e para o tráfico enquanto profissão... Filhos de mães que não tem grandes possibilidades de escolha quanto ao trabalho que desenvolvem... Meninos que já nascem "brigando" contra estatísticas de morte... Vidas que brigam para existir... Quando foi que nos acostumamos com o apagamento dessa história? Walter Benjamin (1987) conseguiu antecipar o que ainda muitos resistem a aceitar: o estado de exceção é vivenciado na carne, no dia a dia; aos vencidos poucas são as possibilidades. $\mathrm{Ou}$ melhor, as possibilidades se dão pela sobrevivência na barbárie. A sobrevivência se dá a partir dos cacos, da barbárie, das ruínas. Narram-se outras coisas a partir da barbárie.

São crianças negras, pobres, periféricas, usuárias de algum serviço da Assistência Social, estudantes de escolas públicas, criadas em um lar chefiado por uma mulher (mãe/avó), que morrem cedo demais... Mulheres que ficam órfãs cedo demais. Infâncias, adolescências e juventudes vividas sempre no risco, sempre no limiar de virar carne de churrasco, como sugere Jonathan Swift (2006) no século XVIII em seu indigesto 'Manual para fazer das crianças pobres churrasco: um texto político e satírico que 
ensina, a partir da ácida crítica que Jonathan faz, sobre como transformar em comida os bebês pobres irlandeses - eliminando ao Estado o custo que existiria para mantê-los, dada sua condição de pobreza e possível mendicância; de forma que virassem alimento para os mais ricos. No Brasil, sabemos quais corpos seriam esses. Já dizia Elza Soares: a carne mais barata do mercado é a carne negra.

Como a dor vira engajamento político? Que conhecimentos são produzidos neste processo? Como a resistência se constitui enquanto prática de cuidado? Como as memórias do cuidado se estabelecem? Como se articula práticas de cuidado maternas com práticas de cuidado pessoais? Como se constituem práticas de cuidado nesse cenário? Nossas interrogações surgem quando acompanhamos histórias de mulheres que transformam seu processo de luto em ativismo e luta pelo direito à justiça e que a barbárie não ocorra com outras mulheres e suas famílias. Uma resistência que passa por garantir sua existência e a sobrevivência para além de todo o processo de sofrimento envolvido.

Vivemos em um cenário de tantas mortes "autorizadas" por uma lógica racista e genocida, que é possível dizer que existe algo pactuado em relações a essas vidas que são feitas morrer. Mbembe (2018) pergunta se a noção de biopoder - "enquanto domínio da vida sobre o qual o poder se estabeleceu controle" - é suficiente para o cenário político contemporâneo que faz da morte do inimigo seu objetivo primeiro. E propõe a noção de necropolítica, enquanto forma contemporânea que subjuga a vida ao poder da morte, para dar conta das formas de morte que vemos no nosso mundo contemporâneo. Em que se faz uso das armas de fogo com o objetivo de provocar a destruição de pessoas. Fazendo o extermínio de populações. Conferindo-lhes o estatuto de "mortos-vivos" (p. 71). Mbembe nos convoca a pensar na relação que essas mortes têm com a noção de raça. "A raça foi a sombra sempre presente no pensamento e na prática das políticas do Ocidente, especialmente quando se trata de imaginar a desumanidade de povos estrangeiros - ou a dominação exercida sobre eles" (2018, p.18). Souza e Gallo (2002), a partir da obra de Foucault, afirmam que

[...] o racismo é o mecanismo pelo qual o Estado justifica seu direito de matar, numa sociedade biopolítica, fundada na afirmação da vida. E o que é mais interessante: o direito de matar é justificado como uma afirmação da própria vida, uma vez que a eliminação do diferente, do menos dotado, do menos capaz implica a purificação da raça, o melhoramento da população como um todo. A cada um que morre, o conjunto resultante é melhor que o anterior. O racismo de Estado é, pois, a feição moderna do evolucionismo e do darwinismo social novecentista ( $\mathrm{p}$. 47).

\section{A centralidade da família na Política de Assistência Social}

São essas famílias mais suscetíveis de serem matadas que são a base do trabalho na Assistência Social. Assim, nos colocamos a pensar como a política entende o seu trabalho social com famílias. A partir delas, tenta-se promover vínculos, palestras, atendimentos, estabelecimento e/ou reconstrução de função protetiva. Todas as ações passam pelas famílias e, para isso, criam-se estratégias. Estratégias para controle? Para proteção? Entre elas, a ideia de responsável familiar: a partir de análise de documentos da Política Nacional de Assistência Social, somos convocadas a pensar sobre essa concepção, no trabalho social com as famílias, no sentido de focar nas mulheres-mães como alvos e como responsáveis que estariam atuando na proteção das famílias. Enquanto isso, quem protege essas mulheres?

Como essas mulheres-mães protegem suas filhas e seus filhos da fome, da violência, da violência de Estado, do genocídio de suas filhas e seus filhos/as negros/as? O que dá 
possibilidade de existência para essas famílias?

A partir dessa ideia de responsável familiar, colocamo-nos a pensar sobre quais efeitos podem ter os entendimentos que responsabilizam as mulheres pela manutenção do cuidado na família, pela manutenção das próprias políticas públicas. Algo que se dá quase que na impossibilidade: exige-se a presença de uma pessoa responsável pela família, exige-se "da família" que esta possa se proteger. E nos ficam as perguntas: é possível que o trabalho com as famílias usuárias das políticas de assistência social seja feito nessa perspectiva, sem que recaia sobre as mulheres-mães a responsabilidade por "falhas"? Se essas mulheres-mães acessam os serviços quando "falharam" em cumprir a função protetiva prévia que é esperada delas, como esse processo se daria de forma a respeitar essas vidas e não as culpabilizar? Com base em que e em quais famílias se constrói o que lhes é cobrado enquanto condição para que sejam consideradas boas famílias?

As autoras Rodrigues e Hennigen (2012) apontam para o grande número de políticas e programas que buscam incentivar certas condutas familiares com a justificativa de assim operar na promoção da saúde, educação, proteção integral de crianças e adolescentes, entre outros aspectos. As autoras afirmam também que além de prever condutas, os programas e políticas de assistência preconizam a família como o melhor lugar para a criança, mas o que não diz respeito a toda e qualquer família (organização familiar), mas sim a um tipo de família ideal, marcada por lugares determinados. E nesse contexto, para existir uma família ideal, seria preciso que essas mulheres-mães desempenhassem papéis vinculados a ideais de mulheres e de maternidades. Que direitos restam a essas mulheres que são imperativamente coladas à figura da maternidade? E figuras maternas específicas, que são isoladamente incumbidas de um papel de proteção, sustento, autoridade - como é dito nos documentos. É fundamental considerarmos os efeitos possíveis dessa construção de saberes e práticas em que essas mulheres seriam naturalmente capazes de exercer cuidado - um cuidado específico, regulado - e em que o cuidado e as políticas de proteção são feminizados. E em que a pobreza e a negritude são criminalizadas.

As mulheres são referência para manutenção de políticas sociais que tem o cuidado familiar como um de seus eixos. As mulheres enquanto mães. Existe lugar possível nesse cenário para as mulheres enquanto cidadãs? Quais são as cidadanias possíveis considerando o exercício da maternidade, das vidas pobres, das vidas negras?

\section{Mães órfãs de filhos mortos cedo demais}

Não temos dúvidas de que essas histórias sobre morte e violência são de conhecimento geral. Todos os dias, nos noticiários esta realidade é estampada: pessoas negras e pobres morrendo de forma violenta. Elas são assassinadas. Se todos/as sabemos dessa realidade, e sabemos, o que faz com que não falemos disso? O que cria a dificuldade imensa de falarmos da barbárie à qual, querendo ou não, não podemos negar um certo costume? O racismo estrutural que permeia nossas instituições e modos de viver promovem o silenciamento de práticas genocidas que acometem principalmente a população negra. Mortes que começam pequenas, com a diminuição do campo de possibilidades dessas vidas e que se aprofundam com a morte física de uma parcela muito específico: jovens negros que morrem de forma violenta. Para a Psicologia Social no campo das Políticas Públicas cabe entender sua parcela de responsabilidade. Como nos situamos frente a este cenário?

Apostamos que uma forma de romper com o silêncio sobre isso que se vê todos os dias e não se fala é a construção dessas histórias, e a circulação, nos espaços acadêmicos inclusive, dessas narrativas de vidas - das que morreram e das sobreviventes. Histórias não-hegemônicas que precisam ser tratadas com o respeito e cuidado, histórias que precisam ser acolhidas e pensadas a partir 
de sua dimensão política. São histórias de testemunho. Como se dá a maternidade de mulheres que são visadas pelas políticas de morte? Mulheres que sobrevivem e que em uma situação-limite (Agamben, 2008) se constituem enquanto testemunhas de uma violência sem tamanho. $\mathrm{O}$ autor vai afirmar que na "situação extrema", o que está em jogo é, portanto, continuar sendo ou não um ser humano. Eliane Brum, contando as histórias do testemunho que fez, nos diz que

Não há hipérboles na gramática das mães vivas. As palavras são exatas. As frases, sem gordura. Selvina pariu doze filhos. Perdeu quatro de tiro. Sobre o quinto não tem certeza, porque sumiu. Outros cinco morreram de doença. Restaram dois. Nesta matemática de perdas, ela não sente saudade dos filhos que partiram por sarampo ou "quebranto". A dor que a devasta é deixada pelos que se foram de "morte matada". Essa, segundo Selvina, é a morte sem esquecimento. (Brum, 2016, pp. 205206).

Esse fragmento é do capítulo "A mãe mutilada", escrito a partir do encontro de Eliane com Selvina. Selvina é uma das mulheres que inspira, através da autora, o início deste ensaio. Início que conta micronarrativas de vidas de mulheres sobreviventes. Histórias de sobrevidas. E a de Selvina estava entre tantas que pôde ter sido pouco guardada na memória, como cada uma outra - dando lugar ao esquecimento. Escolhemos lembrar dela no momento de concluir esse ensaio, também através do testemunho.

A testemunha nunca é neutra ou imparcial. Ela tem a responsabilidade de fazer ver aquilo que teve o privilégio de ver, sentir ou pensar. Ela se torna um criador. De sujeito que percebe (ver), torna-se sujeito criador (fazer ver). Mas isso porque, atrás da testemunha, surge outro personagem, o advogado. É ele quem convoca a testemunha, quem faz com que toda criação se torne um discurso de defesa a favor das existências que ela faz aparecer, ou melhor, comparecer. É preciso dar uma força, uma amplitude para aquilo de que fomos a testemunha privilegiada (Lapoujade, 2017, p.22).

$\mathrm{Na}$ responsabilidade de fazer ver, trazemos essas histórias que são vistas, mas não são problematizadas e enfrentadas enquanto um problema social. São vistas nas notícias, nas ruas, mas pouco são tomadas como material de estudo, ação - ocupam um lugar outro no pensamento. De forma que essa discussão é posta à margem, pelas pessoas, pela Assistência Social, pelas psicologias. A quem interessam essas vidas? A quem interessa esse silenciamento? Vimos que é uma questão ética nos debruçarmos sobre os temas que aqui escolhemos narrar. O racismo que permeia nossas práticas institucionais precisa ser tomado enquanto analisador $\mathrm{e}$ combatido em todas as instâncias. O apagamento da escravidão na memória do Brasil, a dificuldade em acolhermos narrativas de cuidado que subvertam à lógica "esperada" nas políticas públicas e o racismo estrutural no Brasil são alguns dos elementos que contribuem para a produção de mulheres que se tornam órfãs de seus filhos; produção de uma naturalização da morte para uma parcela da população (jovem, pobre e negra, predominantemente masculina). Mas há "mortes" em diferentes níveis... E essas precisam ser pensadas e problematizadas pela Psicologia para que possamos nos ocupar eticamente dos processos de escuta, acolhimento e cuidado neste cenário que apresentamos. 


\section{Referências}

Agamben, G. (2002). Homo sacer: o poder soberano e a vida nua I. Belo Horizonte: UFMG.

Agamben, G. (2008). O que resta de Auschwitz: o arquivo e a testemunha (Homo Sacer III). São Paulo: Boitempo.

Barbosa, P. B. (2017). O filho é da mãe? Fortaleza: Substância.

Benjamin, W. (1987). Obras Escolhidas II Rua de Mão Única. São Paulo: Brasiliense.

Brum, E. (2016). O olho da rua. RS: Arquipélago.

Candiotto, C. (2011). Cuidado da vida e dispositivos de segurança: a atualidade da biopolítica. In G. C. Branco, \& A. VeigaNeto (Orgs.), Michel Foucault: Filosofia \& Política (pp. 81-96). Belo Horizonte/MG: Autêntica.

Didi-huberman. (2011). A sobrevivência dos vaga-lumes. Belo Horizonte: UFMG.

Evaristo, C. (2016). Olhos d'água. Rio de Janeiro: Pallas.

Evaristo, C. (2017). Insubmissas lágrimas de mulheres. Rio de Janeiro: Malê.

Gagnebin, J. M. (2009). Lembrar escrever esquecer. São Paulo: Editora 34.

IPEA. (2018). Atlas da Violência 2018. Rio de Janeiro: IPEA e FBSP.

Lapoujade, D. (2017). As existências mínimas. São Paulo: N-1 edições.

Larrosa, J. (2004). A operação ensaio: sobre o ensaiar e o ensaiar-se no pensamento, na escrita e na vida. Educação e Realidade, 29(1), 27-43. Recuperado de https://seer.ufrgs.br/educacaoerealidade/arti cle/view/25417

Mbembe, A. (2018). Necropolítica. São Paulo: $\mathrm{N}-1$ edições.

Merhy, E. E. (2006). O cuidado é um acontecimento, e não um ato. In I Fórum Nacional de Psicologia e Saúde Pública: contribuições técnicas e políticas para avançar o SUS (pp. 69-78). Brasília/DF: Conselho Federal de Psicologia.

Recuperado de

http://www.crprj.org.br/site/wpcontent/uploads/2016/04/saude-publica.pdf

Rodrigues, L., \& Hennigen, I. (2012). Entre cenas do acolhimento institucional e da adoção: incitamento à vontade de família. In L. R. Cruz \& N. M. F. Guareschi (Orgs.), O psicólogo e as políticas públicas de assistência social (pp. 66-90). Petrópolis/RJ: Vozes.

Souza, R. M., \& Gallo, S. (2002). Por que matamos o barbeiro?: reflexões preliminares sobre a paradoxal exclusão do outro. Educação \& Sociedade, 23(79), 3963. doi: 10.1590/S010173302002000300004

Swift, J. (2006). Manual para fazer das crianças pobres churrasco. Rio de Janeiro: editora do Bispo.

\section{Dados sobre as autoras:}

- Thais Gomes de Oliveira: Graduanda do curso de Psicologia da Universidade Federal do Rio Grande do Sul e Bolsista de Iniciação Científica PIBIC/UFRGS.

- Bruna Moraes Battistelli: Psicóloga, especialista em Instituições em Análise pela Universidade Federal do Rio Grande do Sul (UFRGS), mestra em Psicologia Social e Institucional pelo PPG Psicologia Social e Institucional da Universidade Federal do Rio Grande do Sul (UFRGS). Doutoranda do PPG Psicologia Social e Institucional da Universidade Federal do Rio Grande do Sul (UFRGS). Bolsista CAPES.

- Lílian Rodrigues da Cruz: Psicóloga; doutora em Psicologia pela Pontifícia Universidade Católica do Rio Grande do Sul (PUCRS); docente do Instituto de Psicologia - Departamento de Psicologia Social e Institucional - e do Programa de Pós-Graduação em Psicologia Social e Institucional da Universidade Federal do Rio Grande do Sul (UFRGS). Integra o Núcleo epolitics - Estudos em Políticas e Tecnologias Contemporâneas de Subjetivação. 